\title{
As Dimensões Múltiplas do Comprometimento Organizacional: um Estudo na ECT/MG
}

\author{
Mariana Lima Bandeira \\ Antônio Luiz Marques \\ Ricardo Teixeira Veiga
}

\section{RESUMO}

A inserção do movimento das pesquisas de comprometimento organizacional em uma linha mais abrangente, salientando a nova tendência norte-americana de pesquisar os múltiplos comprometimentos no ambiente de trabalho, constitui uma contribuição importante para trabalhos que abordam o tema num contexto globalizado e dinâmico. Observa-se, especialmente no setor de serviços, a associação da qualidade à demanda por pessoas qualificadas e comprometidas com o trabalho da empresa, de modo que se garanta a satisfação do consumidor em suas necessidades e, conseqüentemente, vantagem competitiva de mercado. Mediante as políticas de recursos humanos, as organizações procuram influenciar, de certa forma, o envolvimento de seus empregados com as metas organizacionais, sendo que esse vínculo pode assumir facetas múltiplas. Daí irrompe este questionamento: até que ponto é possível conseguir esse comprometimento, levando-se em consideração que a empresa estudada pertence ao setor público, mais precisamente a Empresa de Correios e Telégrafos - ECT. O presente trabalho pretendeu responder a essa questão central, conduzindo a pesquisa por meio do modelo de três dimensões de Meyer e Allen (1984, 1991, 1997) e do estabelecimento de padrões diversificados de comprometimento organizacional.

Palavras-chaves: comprometimento organizacional; recursos humanos; empresa pública; comportamento organizacional.

\section{Abstract}

The Human Resource Management - HRM, in fact, tries to influence the commitment in the workplace, and this attachment may assume multiple means, that are examined here as the links that workers have been established between the various forms of commitment and organizational behavior. So, the main purpose of this paper is to test the Meyer and Allen $(1984,1991,1997)$ three-component model in a public company of Brazil, looking over how it could appear in that context. At the end of this research some other patterns of commitment in the workplace were discovered, showing a new perspective in organizational researches.

Key words: organizational commitment; human resource management; public company; organizational behavior. 


\section{INTRODUÇÃO}

Apresenta-se, no cenário atual, uma conjuntura em que tanto as empresas quanto seus funcionários tomam consciência das mudanças revolucionárias emergentes que alteram o nível de exigências individuais e organizacionais. Essa variação de padrões exige uma busca constante de diferenciais que coloquem os atores sociais em destaque no mercado global. Nesse sentido, o setor terciário vem mostrando interesse cada vez maior em desenvolver a diversificação e a qualidade em sua prestação de serviços e gestão de pessoal, com vistas a um desempenho e produtividade mais significativos.

Mediante as políticas de recursos humanos, as empresas procuram estabelecer uma comunicação com seus empregados e, de certa forma, tentam influenciar o comportamento e o envolvimento deles no ambiente organizacional. O questionamento que emerge daí é este: até que ponto é possível conseguir o comprometimento e quais as estratégias que mais se destacam na empresa, para se atingirem tais objetivos.

O comprometimento organizacional, em linhas gerais, pode ser entendido como forte vínculo do indivíduo com a organização, que o incita a dar algo de si, a saber: sua energia e lealdade. O presente panorama sócio-econômico leva a refletir, no entanto, sobre a melhor forma de se conquistar esse vínculo, diante da crise que se acentua no cenário mundial. Nesse quadro, como objetivo geral, pretendeu-se verificar e avaliar em que medida o processo de gestão de recursos humanos, praticado numa empresa de serviços do setor público, contribui para desenvolver e manter o comprometimento do empregado com ela, estabelecendo-se ainda padrões de comprometimento da amostra.

\section{Panorama Térico do Comprometimento Organizacional}

Comprometimento apresenta características peculiares, quando analisado sob a ótica da dimensão acadêmica e organizacional, abrangendo diversos elementos no ambiente de trabalho (Bastos, 1994).

O termo foi definido de forma a gerar diversas interpretações, consistindo em atitude ou orientação para a organização, que une a identidade da pessoa à empresa. Pode ser um fenômeno estrutural que ocorre como resultado de 
transações entre os atores organizacionais; ou um estado em que o indivíduo se torna ligado à organização por suas ações e crenças ou ainda a natureza do relacionamento de um membro com o sistema como um todo.

Ainda que não tenha um conceito único, o propósito básico dos teóricos temse restringido a delimitar e identificar seus determinantes de modo a direcionar esforços para envolver o ser humano integralmente com a organização e atingir maiores escores de produtividade.

Apesar de a maioria das pesquisas concentrar seus esforços nos enfoques afetivo-atitudinal e instrumental, as demais vertentes apresentam contribuições igualmente valiosas para o aprimoramento do tema. As abordagens mais relevantes para a compreensão do modelo adotado por esta pesquisa são discutidas separadamente, a seguir. Salienta-se que todas as propostas apresentam um ponto comum: partem da premissa de que o vínculo do indivíduo com a organização existe e é inevitável. Diferem apenas na forma como este vínculo se desenvolve e se mantém no ambiente organizacional. Conferem ainda valor para o fato de que altos níveis de comprometimento trazem resultados positivos para a organização e seus membros.

\section{Enfoque Afetivo-Atitudinal}

Constitui a linha de pesquisa mais utilizada na investigação acadêmica, cujas bases se encontram nas teorias de Etzioni (1975), tendo sido desenvolvida a partir dos trabalhos de Mowday, Steers e Porter (1982).

A premissa básica do enfoque afetivo, como o próprio nome indica, revela a identificação do indivíduo com as metas organizacionais, bem como a introjeção de seus valores, assumindo-os como próprios (Mowday, Steers e Porter, 1982). Os autores complementam essa definição com o sentimento de lealdade, desejo de pertencer e se esforçar pela empresa, sendo tais dimensões mensuradas por meio de uma escala de atitudes.

Sob esse ponto de vista, o indivíduo assume uma postura ativa, em que se parte da suposição de que ele deseja dar algo de si para a organização. $\mathrm{O}$ comprometimento organizacional, então, representa um vínculo muito mais forte com a organização nesta perspectiva, considerando que a dimensão afetiva se alimenta e sedimenta nos sentimentos do empregado, aceitação de crenças, identificação e assimilação de valores da organização.

\section{Enfoque Normativo}

Essa abordagem fundamenta-se principalmente nas pesquisas desenvolvidas 
por Weiner (1982) e Weiner e Vardi (1990) e procura trabalhar o plano organizacional por meio da análise da cultura, e o plano individual mediante os processos motivacionais. Pressupõe que o comportamento do indivíduo é conduzido de acordo com o conjunto de pressões normativas que ele assume internamente. O comprometimento, então, é um vínculo do trabalhador com os objetivos e interesses da organização, estabelecido e perpetuado por essas pressões normativas.

Faz-se mister destacar, entretanto, que essa adesão vai depender dos valores e normas partilhados e do que os membros acreditam ser a conduta ética e moral. O modelo de Wiener (1982), conhecido como normativo-instrumental, afirma que o comportamento humano está vinculado a esses valores e costumes recebidos ao longo da vida que, aliados às crenças instrumentais (recompensas), justificariam as intenções comportamentais que predizem o comprometimento organizacional. Os autores postulam ainda o comportamento humano sendo determinado por dois fatores: o atitudinal (atitude como resultado da avaliação dos resultados da ação) e o normativo (percepção da ação como resultado de pressões normativas, geralmente da cultura da empresa).

\section{Enfoque Instrumental}

O enfoque instrumental originou-se nos trabalhos de Becker (1960), traduzindo o comprometimento como função da percepção do trabalhador quanto às trocas estabelecidas enquanto parte integrante da organização. Esse modelo assume que o empregado opta por permanecer na empresa, enquanto perceber benefícios nessa escolha. Caso os investimentos realizados por ele sejam maiores que o retorno obtido, sua escolha certamente será a do abandono da organização.

Esse constitui o segundo grande referencial teórico adotado nas pesquisas sobre o tema e possui outros nomes, além do já conhecido enfoque instrumental: calculativo, continuação, side-bets ${ }^{(1)}$ (Bastos, 1994).

Na ótica de Bastos (1993, p. 56), o comprometimento nessa abordagem "seria, então, um mecanismo psicossocial, cujos elementos side-bets ou conseqüências de ações prévias - recompensas ou custos - impõem limites ou restringem ações futuras".

Os trabalhos de Meyer e Allen (1984) enriqueceram essa abordagem, ao desenvolvê-los levando-se em conta ambos os enfoques: afetivo e instrumental. 


\section{O Modelo de Três Dimensões de Meyer e Allen}

O ponto em comum das definições de comprometimento organizacional consiste em ser um estado psicológico que caracteriza a relação do indivíduo com a organização. O que os diferencia é a natureza desse estado e, a partir dessa constatação, Meyer e Allen (1991) preconizaram o modelo de três dimensões: afetivo, instrumental e normativo. Os autores enfatizam que o comprometimento pode assumir diferentes formas, de acordo com as entidades relacionadas, quais sejam: grupo de trabalho, supervisor, carreira, sindicato. Essas dimensões correspondem a componentes, e não a tipos de comprometimento.

Meyer e Allen (1991, p. 67) sintetizam os conceitos da seguinte forma: "Empregados com um forte comprometimento afetivo permanecem na organização porque assim o querem.[...] Aqueles cuja ligação está baseada no comprometimento instrumental continuam empregados porque precisam. [...] Empregados com alto grau de comprometimento normativo sentem que eles devem permanecer na organização"(2).

Por meio de uma análise longitudinal, procuraram identificar os fatores antecedentes do comprometimento organizacional; o resultado de suas pesquisas convergiu para a elaboração do modelo de três dimensões: o afetivo, o instrumental e o normativo. Chegaram também à conclusão de que as escalas de RitzerTrice e Hrebiniak-Alluto possuíam maior dependência do comprometimento afetivo do que do instrumental (Meyer e Allen, 1984), negando de certa forma a proposta inicial de Becker (1960) e reafirmando o componente normativo do comprometimento. Os autores demonstraram que, embora sejam distintos, o comprometimento normativo e afetivo apresentam uma interdependência. Tal fato não é observado nos dois primeiros, uma vez que são relacionados a antecedentes diferentes. Desenvolveram, então, dois questionários com o objetivo de medir o comprometimento afetivo e o instrumental.

Entretanto alertam para o fato de que a generalização para outros domínios, o sindicato, por exemplo, não foi testada empiricamente, conforme Meyer e Allen (1997), sendo interessante fazer especulações a respeito. Os autores argumentam que, embora o compromisso com o sindicato seja descrito como essencialmente afetivo, é possível que seus membros desenvolvam outros tipos de estados psicológicos, característicos das dimensões normativa e instrumental.

McGee e Ford (1987) realizaram um exame das propriedades psicossométricas das escalas desenvolvidas por Meyer e Allen (1984), por meio da técnica de análise fatorial, usando a solução com dois fatores. O primeiro fator foi formado pelos 8 itens da escala do comprometimento afetivo, possuindo cargas fatoriais aceitáveis; o segundo fator era composto pelos 8 itens da escala do comprometi- 
mento instrumental, mas apenas 6 possuíam cargas aceitáveis. Assim, surgiu uma nova dimensão do comprometimento, batizada de normativa, com itens que refletiam o sacrifício pessoal do empregado na hipótese de deixar a organização. Segundo Weiner (1982, p. 419), indivíduos comprometidos possuem certos comportamentos, porque "acreditam que é certo e moral fazê-lo".

Em trabalho posterior de Meyer e Allen (1991), houve a incorporação da dimensão encontrada, a normativa, apresentando as diferenças conceituais em torno do comprometimento organizacional. Essa nova perspectiva permitiu a Somers (1995) tratar dos conseqüentes do comprometimento - intenção de permanecer no emprego, rotatividade e absenteísmo - relacionando-os com as três dimensões: afetiva, normativa e instrumental. "Depois de um longo período em que a pesquisa do comprometimento foi focalizada quase que exclusivamente num apego afetivo às organizações, uma nova perspectiva baseada no modelo de múltiplos componentes de comprometimento está emergindo" (Somers, 1995, p. 54).

Ainda há Cohen (apud Meyer e Allen, 1997), que também comprovou o valor da abordagem múltipla do comprometimento. Ele conduziu uma pesquisa entre executivos de três organizações, procurando identificar o sentimento relacionado à empresa, profissão, sindicato e trabalho. Os achados do autor deram sustentação à hipótese de que um comportamento concernente a uma das variáveis pode ser melhor predizente do comprometimento relacionado àquela variável. Dá o exemplo de que o melhor predizente da intenção de deixar a empresa consiste no comprometimento organizacional, ao passo que o comprometimento com o sindicato é o melhor predizente do sucesso da entidade.

Como se vê, a tendência no campo de pesquisa do comportamento humano parece significar que o comprometimento seja tratado à luz das três dimensões conceituais aqui descritas.

\section{Comprometimento Organizacional e Políticas de Recursos Humanos}

Os estudos que focalizam a correlação das políticas de recursos humanos com o comprometimento organizacional são recentes e, por isso mesmo, pouco consistentes em sua totalidade. Observa-se principalmente a preocupação com práticas isoladas (Meyer e Allen, 1997), e poucas pesquisas abrangem o sistema de recursos humanos em sua totalidade.

Com o objetivo de construir a predisposição inicial ao comprometimento de um novato, as organizações apelam para a socialização e treinamento, assevera Wanous (1992). Durante o processo de socialização, as mensagens transmitidas 
aos recém-admitidos parecem mais significativas para determinar e fortalecer o comprometimento do que as características estruturais dessas práticas (Ashforth e Saks, 1996).

O treinamento também faz parte dessa dinâmica organizacional, uma vez que inevitavelmente influencia o vínculo do empregado com a empresa da qual faz parte (Tannenbaum et al., 1991). Nessa linha, Saks (1995) argumenta, fundamentado em suas pesquisas, que os efeitos do treinamento podem ser atribuídos, em parte, aos efeitos do sentimento de competência pessoal que os novatos apresentam ao desempenhar uma tarefa requisitada.

No Brasil, foi conduzida recentemente uma investigação por Sá e Lemoine (1998) com o intuito de conhecer os efeitos do estilo de liderança no comprometimento organizacional. Os autores estabeleceram dois modelos básicos de organizações nos quais basearam sua iniciativa. O taylorista, que se apóia na burocracia e, assim, padroniza a conduta individual dos empregados, provocando uma previsibilidade de ações típica das organizações burocráticas e influenciando negativamente as interações pessoais no ambiente de trabalho. O modelo gerencial (managerial), pelo contrário, valoriza e estimula a simplicidade das relações humanas e a confiança entre os membros, motivando a cooperação, a participação e a iniciativa dos subordinados. A comparação entre os dois modelos permitiu a Sá e Lemoine (1998) afirmarem que o estilo gerencial responde favoravelmente àquilo que se refere à identificação positiva e construtiva do funcionário com a empresa.

Há ainda os que questionam o sentido de conformismo implícito no sentido do comprometimento, investigando a forma como as organizações lançam uso dessa faceta do constructo. Steil e Sanches (1998) asseveram que o comprometimento tem sido utilizado como estratégia de controle dos dirigentes, argumentando que algumas definições conceituais fundamentam essa assertiva. As autoras reforçam que não há economia de esforços para moldar e fortalecer comportamentos desejáveis segundo os interesses das organizações. Dão especial destaque às práticas de recrutamento e seleção; apesar de não ter sido provado possível apontar as tendências para o sentimento de compromisso, elas têm procurado uma sofisticação técnica de modo a eliminar os candidatos não propensos à assiduidade, ao bom desempenho e à permanência na empresa. Esse processo é complementado por meio da socialização, programas de treinamento e qualidade de vida no trabalho.

A maioria das pesquisas procurou focalizar práticas específicas da gestão de recursos humanos, não se preocupando com os efeitos da fragmentação nos resultados e conclusões. Investigá-las de forma isolada pode não refletir a realidade da instituição, indicando, às vezes, um diagnóstico representativo apenas de 
um determinado setor. A gestão de recursos humanos é um complexo de ações independentes que atuam de forma interdependente dentro da organização, sendo ainda parte integrante das estratégias empresariais.

\section{A EMPRESA}

Conquanto pertença ao setor público de serviços, a empresa escolhida é dotada de certa autonomia em muitas de suas atividades e responsabilidades. Possui seu desenvolvimento auto-sustentado, não precisando de qualquer incentivo financeiro ou subsídio do Governo Federal. Tal situação pôde ser observada após mudanças significativas na década de 70, época em que o antigo Departamento de Correios e Telégrafos - DCT, foi transformado em Empresa de Correios e Telégrafos - ECT, com personalidade jurídica própria e novas bases de ação, voltadas para a produtividade e sucesso.

A impressão resultante das entrevistas reforça o ideal de mudança nos modelos de gestão: de um sistema autocrático e impregnado de disciplina militar para outro, participativo, democrático, pró-ativo. Essa necessidade de modernizar foi identificada como fundamental para a manutenção do espaço no mercado e vem acompanhada do uso de estratégias de marketing mais agressivas e da preocupação em ter diferencial competitivo que seja percebido pelo cliente.

A área de recursos humanos (RH) tem o escopo de provocar algumas mudanças de forma a criar respostas adequadas às demandas externas. As políticas de RH da Empresa de Correios e Telégrafos, entretanto, seguem padrões tradicionais, apresentando subgerências específicas para cada função que exercem. O concurso público, desde a promulgação da Constituição do Brasil em 1988, constitui o principal método de recrutamento e seleção, estando a decisão de contratação vinculada ao parecer final do Governo Federal. Assim também ocorre com a progressão na carreira, já que a mobilidade funcional pode ser conseguida apenas por meio dos concursos. Pode-se afirmar, então, que não existe um plano de carreira na ECT.

A estrutura hierárquica e o sistema de cargos e salários são considerados antigos e precisam de reformulação urgente. Obviamente qualquer modificação nesses aspectos requer concordância de órgãos superiores, sendo esse processo moroso, mas adequado ao sistema burocrático do Estado. O piso salarial encontra-se em um patamar razoável e os benefícios oferecidos pela empresa parecem adequar-se às necessidades dos funcionários. 
A integração dos funcionários - novos e antigos - é feita por uma subgerência especialmente voltada para essa área, que promove lazer, eventos culturais e esportivos. As atividades de treinamento e desenvolvimento são de responsabilidade de outra subdivisão da área de RH, que se esforça para melhorar a qualidade de vida e dos serviços de seus profissionais. Os cursos oferecidos podem ser específicos ou gerais e buscam abranger todos os níveis hierárquicos. As relações de trabalho são gerenciadas de forma a manter o clima de satisfação dentro da ECT, reforçando a postura da empresa de preocupação em atuar numa linha humana, que entende o indivíduo como parte essencial da missão organizacional e, conseqüentemente, elemento primordial de competitividade.

\section{Metodologia}

Esta pesquisa pode ser classificada como estudo descritivo, entendendo-se, ainda, que este trabalho esteja enquadrado no estudo de casos. Gil (1987) caracteriza-o pelo aprofundamento de um ou poucos objetos, visando a um conhecimento mais preciso acerca de sua realidade.

A atual pesquisa foi conduzida na Regional Belo Horizonte da Empresa de Correios e Telégrafos. O universo da pesquisa consistiu, então, no corpo de funcionários do contingente efetivo na capital, totalizando 2.739 pessoas.

O cálculo da amostra se deu por meio de procedimentos estatísticos apropriados, com nível de confiança de $95 \%$ e foi obtida aleatoriamente, podendo assim ser considerada estatisticamente representativa da população estudada. A definição da amostra incluiu todos os grupos funcionais existentes na empresa (nível básico, médio-técnico e superior) sendo estratificada nesses níveis. Conquanto o resultado amostral tenha perfeito o total de 580 funcionários, decidiuse aplicar 600 questionários, por questões de praticidade.

Inicialmente procedeu-se a uma análise documental por meio de leitura e exame de relatórios, documentos, manuais, ou fontes secundárias, com o objetivo de aprofundar as informações obtidas em entrevistas com profissionais da empresa estudada, principalmente com os representantes da área de recursos humanos.

Após identificadas as políticas de recursos humanos e suas particularidades, a fase seguinte consistiu em elaborar e aplicar um questionário à amostra predefinida e representativa da população de subordinados, supervisores e gerentes, procurando identificar o tipo e os padrões de comprometimento organizacional da empresa. 
O instrumento foi construído baseando-se nos trabalhos de Moraes e Marques (1996), Meyer e Allen (1997) e Medeiros (1997) e nas entrevistas feitas. O questionário combinou itens fechados e abertos, sendo que as questões fechadas encerram a característica de serem medidas em escala tipo Likert, admitindo valores de 1 a 5 . Aborda itens que avaliam o grau de comprometimento instrumental, afetivo e normativo e questões específicas sobre as políticas salariais, plano de carreira, práticas de treinamento e desenvolvimento, processo de admissão e forma de organização do trabalho da instituição estudada.

A estratégia de tratamento dos dados consistiu em análise quantitativa, sendo conduzida por meio de processo multivariado de tratamento dos dados. Esses foram analisados com o auxílio do pacote estatístico SPSS, versão 7.5 para Windows. A escolha da abordagem multivariada deveu-se ao fato de a pesquisa utilizar várias escalas para se medir o comportamento humano: comprometimento organizacional e opiniões acerca dos diversos aspectos da política de RH praticada na empresa. A análise fatorial foi utilizada para estabelecer as dimensões de comprometimento e os escores fatoriais observados para os indivíduos presentes na amostra. A análise de cluster serviu para agrupar os indivíduos de acordo com o grau e a dimensão presente em cada um dos respondentes. A aplicação da análise de variância permitiu identificar as diferenças entre os grupos. O uso da tabulação cruzada entre as dimensões de comprometimento organizacional e alguns dados descritivos auxiliou na sua caracterização completa. E finalmente, o estabelecimento da correlação bivariada aferiu a interferência das práticas de RH no comprometimento observado.

\section{AnÁlise e Discussão dos Resultados}

A correlação bivariada utilizada para as escalas de comprometimento organizacional e recursos humanos mostrou que a maior parte das práticas tradicionais exercem influência nas dimensões do constructo em foco. Isso permite afirmar que há uma relação linear positiva entre as variáveis analisadas. Na Tabela 1, a seguir, é possível comprovar tal assertiva por meio dos coeficientes de Pearson, que apresentam valor positivo, indicando que as variáveis se influenciam diretamente umas às outras.

De acordo com a tabela, o recrutamento e seleção da empresa possui correlação muito pequena com todos os componentes do comprometimento, implicando que essa prática de RH não interfere significativamente no nível de comprometimento dos empregados. O maior índice, no entanto, pertence ao grupo dos comprometidos normativamente $(0,217)$. 


\section{Tabela 1: Coeficiente de Pearson}

\begin{tabular}{l|c|c|c}
\hline & Normativo & Afe tivo & Instrumental \\
\hline Ambiente de Trabalho & 0,393 & 0,409 & 0,034 \\
\hline Carreira & 0,511 & 0,376 & 0,066 \\
\hline Comunicação e Ambiente Físico & 0,412 & 0,373 & 0,076 \\
\hline Recrutamento e Seleção & 0,217 & 0,049 & 0,123 \\
\hline Relacionamento com a chefia & 0,471 & 0,447 & 0,096 \\
\hline Salário & 0,467 & 0,305 & 0,210 \\
\hline Treinamento e Desenvolvimento & 0,505 & 0,514 & 0,073 \\
\hline
\end{tabular}

Fonte: dados da pesquisa.

O vínculo instrumental possui o foco direcionado para as trocas que ele faz salário, tempo investido, entre outras. Assim, infere-se que o aspecto da administração de RH que mais importa para tal categoria seria a política salarial. O comprometimento instrumental apresentou fraca correlação com todas as variáveis, sendo o salário seu maior indicador $(0,210)$ e destacando a pouca importância das práticas de RH na manutenção desse comprometimento. Verifica-se que a maior correlação do salário refere-se à dimensão normativa.

Conquanto essas observações sejam verdadeiras, torna-se evidente que todas as variáveis de recursos humanos investigadas influenciam as dimensões normativa e afetiva do comprometimento, apresentando correlações significativas. Os índices mais elevados são observados nas atividades de treinamento e desenvolvimento (0,514 para comprometimento afetivo e 0,505 para o normativo). Tal fato denota que tais práticas constituem fator primordial dentro do corpo funcional, no que se refere a manter os estilos de comprometimento apontados, fundamentando a preocupação atual da empresa e a tendência do cenário externo de dar atenção especial ao treinamento do empregado. O relacionamento com a chefia é importante também para as duas dimensões, assim como o ambiente social de trabalho, apresentando coeficiente de Pearson entre 0,393 e 0,471.

Quanto ao ambiente físico e comunicação, o comprometimento normativo apresentou índice no âmbito de 0,412 , e o comprometimento afetivo assumiu a pontuação de 0,373 , reforçando o resultado da linearidade positiva das correlações observadas anteriormente.

Complementando a análise, é possível constatar ainda que a carreira possui maior significância para o comprometido normativamente, seguindo-se o treinamento e desenvolvimento. Esta dimensão do comprometimento obteve as 
maiores correlações, permitindo avaliá-la como fortemente influenciada pelas práticas de $\mathrm{RH}$.

A próxima etapa a ser seguida consistiu no estabelecimento dos padrões de comprometimento observados na amostra. Antes, porém, será utilizado o resultado da análise fatorial de modo a relembrar a estrutura tridimensional do comprometimento organizacional (vide Tabela 2).

Tabela 2: Dimensões do Comprometimento Organizacional

\begin{tabular}{c|c|c}
\hline Normativo & Afetivo & Instrumental \\
\hline CNORM3 & CAF2 & CINSTR1 \\
\hline CNORM5 & CAF3 & CINSTR2 \\
\hline CNORM6 & CAF5 & CINSTR3 \\
\hline CAF1 & CAF6 & CINSTR5 \\
\hline CAF4 & CNORM1 & CINSTR6 \\
\hline CAF7 & & \\
\hline CINSTR4 & & \\
\hline
\end{tabular}

Fonte: dados da pesquisa.

A partir do estabelecimento e da confirmação desses três fatores, foi extraído um escore fatorial para cada indivíduo. Procedeu-se, então, a uma distribuição de freqüência para analisar como cada fator encontrado estava distribuído na amostra. Para comprometimento afetivo, os escores variaram de -3.888 a 1,922, com mediana valendo 0,142 . A variação observada no comprometimento normativo assumiu valores entre $-3,222$ e 2,103 e sua mediana foi de 0,261; finalmente, os escores de instrumentalidade ficaram entre $-3,181$ e 1,951, com mediana 0,647 (vide Tabela 3).

Tabela 3: Estatísticas Referentes à Distribuição dos Escores Fatoriais

\begin{tabular}{l|c|c|c|c}
\hline \multicolumn{1}{c|}{ DIM ENSÃO } & MÍNIMO & MED IANA & QUARTIL 75\% & MÁXIMO \\
\hline NORMATIVA & $-3,322$ & 0,261 & 0,713 & 2,103 \\
\hline AFETIVA & $-3,888$ & 0,142 & 0,765 & 1,922 \\
\hline INSTRUMENTAL & $-3,181$ & 0,647 & 0,744 & 1,951 \\
\hline
\end{tabular}

Fonte: dados da pesquisa.

Constata-se, assim, que muitos indivíduos se inserem em mais de uma dimensão, pois os escores fatoriais positivos estiveram presentes em mais de um tipo de comprometimento. A análise de cluster fez-se necessária, acompanhando de certa forma a metodologia utilizada por Medeiros (1997). Com o objetivo de 
separar os indivíduos em padrões específicos de comprometimento, os grupos foram definidos segundo as categorias desenvolvidas pelo autor (vide Tabela 4).

\section{TABELA 4: Caracterização dos Clusters}

\begin{tabular}{c|l}
\hline GRUPO & \multicolumn{1}{c}{ CARACTERIZAÇÃO } \\
\hline 1 & Comprometido nas três dimensões \\
\hline 2 & Descomprometido nas três dimensões \\
\hline 3 & Comprometidos Normativamente (somente) \\
\hline 4 & Comprometidos Afetivamente (somente) \\
\hline 5 & Comprometidos Instrumentalmente (exclusivo) \\
\hline 6 & Comprometidos Normativa-Afetivamente \\
\hline 7 & Comprometidos Normativa-Instrumentalmente \\
\hline 8 & Comprometidos Afetiva-Instrumentalmente \\
\hline
\end{tabular}

Fonte: Medeiros, 1997.

Os dados para que a análise de cluster pudesse iniciar as interações foram alocados em outro arquivo do SPSS, utilizando-se os valores do quartil 75\% e da mediana (vide Tabela 3). As medianas simbolizavam a não-representatividade da dimensão, ao passo que os valores do quartil 75\% eram determinantes da dimensão que se desejava destacar. Tais valores são denominados centróides dos grupos. Obteve-se, então, a Tabela 5 como resultado:

\section{Tabela 5: Classificação Final da Análise de Cluster}

\begin{tabular}{r|l|r|r|r|c|c}
\hline $\mathbf{N r}$ & \multicolumn{1}{|c|}{ Identificação } & Normativo & Afetivo & Instrumental & Casos & \% \\
\hline $\mathbf{1}$ & $\begin{array}{l}\text { Comprometido nas três } \\
\text { dimensões }\end{array}$ & 1,0672 & 0,85852 & 1,16805 & 13 & 3,2 \\
\hline $\mathbf{2}$ & $\begin{array}{l}\text { Descomprometido nas três } \\
\text { dimensões }\end{array}$ & $-0,58422$ & $-0,54312$ & $-0,46499$ & 121 & 29,4 \\
\hline $\mathbf{3}$ & $\begin{array}{l}\text { Comprometido } \\
\text { Normativamente (somente) }\end{array}$ & 1,09338 & $-0,60171$ & $-0,37479$ & 61 & 14,8 \\
\hline $\mathbf{4}$ & $\begin{array}{l}\text { Comprometido } \\
\text { Afetivamente (somente) }\end{array}$ & $-0,47666$ & 0,96766 & $-0,45672$ & 79 & 19,20 \\
\hline $\mathbf{5}$ & $\begin{array}{l}\text { Comprometido } \\
\text { Instrumentalmente (somente) }\end{array}$ & $-0,47936$ & $-0,72989$ & 1,18067 & 50 & 12,2 \\
\hline $\mathbf{6}$ & $\begin{array}{l}\text { Comprometido Normativa- } \\
\text { Afetivamente }\end{array}$ & 1,04936 & 0,82516 & $-0,34325$ & 39 & 9,5 \\
\hline $\mathbf{7}$ & $\begin{array}{l}\text { Comprometido Normativa- } \\
\text { Instrumentalmente }\end{array}$ & 1,07865 & $-0,33372$ & 1,18921 & 23 & 5,6 \\
\hline $\mathbf{8}$ & $\begin{array}{l}\text { Comprometido Afetiva- } \\
\text { Instrumentalmente }\end{array}$ & $-0,55954$ & 1,07221 & 1,08098 & 25 & 6,1 \\
\hline & TOTAL & & & & $\mathbf{4 1 1}$ & $\mathbf{1 0 0 , 0}$ \\
\hline
\end{tabular}

Fonte: dados da pesquisa. 
O grupo 2 destacou-se pelo grande número de casos observados: 121, considerado elevado para a empresa; entretanto, se for analisado tomando-se por referência todos os padrões, implica dizer que os funcionários totalmente descomprometidos representam apenas $30 \%$ dos participantes. O Gráfico 1 promove uma visualização da distribuição dos escores fatoriais entre os grupos identificados.

\section{Gráfico 1: Distribuição dos Escores Fatoriais entre os Grupos}

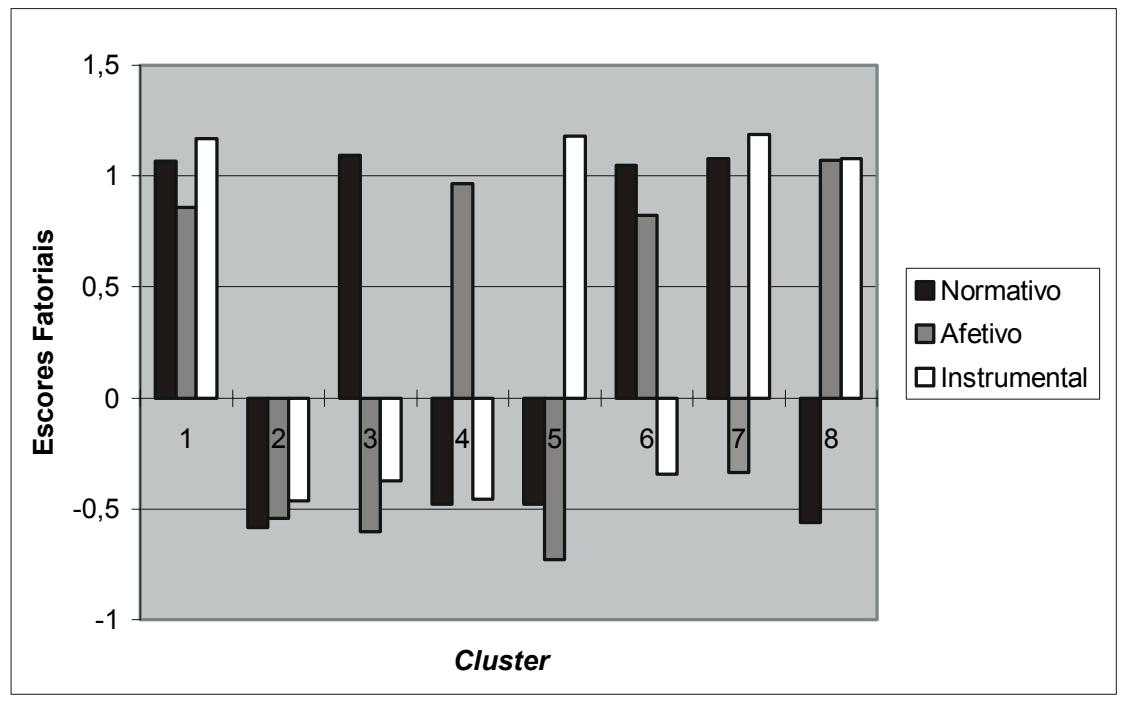

A análise de variância - ANOVA - foi a técnica estatística utilizada para encontrar as diferenças existentes entre os grupos com relação às práticas de recursos humanos da Empresa de Correios e Telégrafos. Antes, porém, foi necessário avaliar a homogeneidade da variância da amostra estudada, de forma a averiguar se a técnica em foco poderia ser utilizada.

Os níveis de significância de todas as dimensões de RH foram maiores que 0,05 , de acordo com a Tabela 6 , permitindo não rejeitar a hipótese nula de que as variâncias sejam iguais (Norusis, 1997) e indicando, ainda, que a análise da variância pode ser aplicada na pesquisa com resultados confiáveis.

O processo utilizado para a análise em discussão foi o One-Way ANOVA, por meio do método Least Significative Difference - LSD. A hipótese nula - Ho, nesse caso, consiste em testar se as médias dos grupos são semelhantes e significativas, propiciando que se façam comparações bem fundamentadas sobre os escores observados para cada grupo. Avaliando-se os valores assumidos por F, juntamente com os respectivos graus de liberdade, observou-se que estes se apresentam com valores superiores ao F crítico, implicando que existem diferenças 
entre os grupos. Como os níveis de significância nas dimensões de RH são menores que 0,05 , as diferenças são consideradas estatisticamente relevantes (Norusis, 1993), concluindo pela rejeição de Ho.

Tabela 6: Teste de Homogeneidade

\begin{tabular}{l|c|c|c|c}
\hline & $\begin{array}{c}\text { Teste de } \\
\text { Levene }\end{array}$ & $\mathrm{df1}$ & $\mathrm{df2}$ & \multicolumn{1}{l|}{ Sig. } \\
\hline RH_AMBTR & 1,950 & 7 & 403 &, 061 \\
RH_CARRE &, 425 & 7 & 403 &, 886 \\
RH_COMAF & 1,189 & 7 & 403 &, 308 \\
RH_RCSEL & 1,344 & 7 & 403 &, 228 \\
RH_RLCHF & 1,538 & 7 & 403 &, 153 \\
RH_SAL &, 752 & 7 & 403 &, 628 \\
RH_TD & 1,990 & 7 & 403 &, 055 \\
\hline
\end{tabular}

Fonte: dados da pesquisa

As comparações entre as médias dos padrões de comprometimento foram feitas a partir da tabela das múltiplas comparações ${ }^{(3)}$ e da Tabela 7, a seguir, que estabelece as médias das dimensões de recursos humanos por padrão de comprometimento organizacional. É importante destacar que os grupos que não tiveram diferença significativa implicam uma situação em que os escores médios podem ser considerados semelhantes e, assim, a importância dada à prática de RH apresenta certa homogeneidade entre eles.

Tabela 7: Distribuição Média de RH por Cluster

\begin{tabular}{l|c|c|c|c|c|c|c|c}
\hline & $\mathbf{1}$ & $\mathbf{2}$ & $\mathbf{3}$ & $\mathbf{4}$ & $\mathbf{5}$ & $\mathbf{6}$ & $\mathbf{7}$ & $\mathbf{8}$ \\
\hline $\begin{array}{l}\text { Ambiente de } \\
\text { Trabalho }\end{array}$ & 4,4308 & 3,4579 & 3,8230 & 4,0886 & 3,3560 & 4,2103 & 4,1304 & 3,9600 \\
\hline Carreira & 3,6813 & 2,7993 & 3,3864 & 3,2134 & 2,4829 & 3,7509 & 3,6025 & 2,9829 \\
\hline $\begin{array}{l}\text { Comunicação e } \\
\text { Ambiente Físico }\end{array}$ & 4,2479 & 3,3719 & 3,8124 & 3,6906 & 3,1511 & 4,1595 & 3,9614 & 3,8978 \\
\hline $\begin{array}{l}\text { Recrutamento e } \\
\text { Seleção }\end{array}$ & 4,5128 & 3,8540 & 4,2404 & 3,9916 & 4,0267 & 4,2991 & 4,3913 & 4,0400 \\
\hline Relação com Chefia & 4,5481 & 3,4528 & 3,8975 & 3,9684 & 3,2650 & 4,2949 & 4,4076 & 3,9350 \\
\hline Salário & 3,9231 & 2,4153 & 3,1148 & 2,6899 & 2,2650 & 3,2692 & 3,6196 & 2,8800 \\
\hline $\begin{array}{l}\text { Treinamento e } \\
\text { Desenvolvimento }\end{array}$ & 4,5266 & 3,5906 & 4,0845 & 4,1558 & 3,5877 & 4,5010 & 4,3512 & 4,1538 \\
\hline
\end{tabular}

Fonte: dados da pesquisa. 
Observou-se que os grupos 2 - descomprometidos nas três dimensões - e 5 comprometido instrumentalmente - obtiveram escores médios baixos em todas as práticas de $\mathrm{RH}$, se comparados aos outros padrões de comprometimento. Ainda que em algumas dimensões de RH analisadas, a média tenha sido superior a 3 , é possível inferir que as práticas de RH não influenciam muito o comportamento dos indivíduos que se inserem nesses agrupamentos -2 e 5 . O processo de recrutamento e seleção também não apresentou diferenças significativas entre os grupos. Como foram baixos os coeficientes de correlação bivariada, optou-se por não analisar as médias dessa variável de RH.

O treinamento e desenvolvimento, prática que se destacou nos coeficientes de correlação observados anteriormente, não apresentou muitas diferenças entre os padrões de comprometimento. Pode-se dizer, no entanto, que os funcionários pertencentes ao grupo 1 - comprometidos em todas as dimensões - tiveram as maiores médias na dimensão de RH em foco. Esse fato significa dizer que o treinamento e desenvolvimento exerce mais influência neste grupo, se comparado aos grupos 3, comprometidos normativamente; 4, comprometidos afetivamente; e 8, comprometidos afetiva-instrumentalmente. Destaque também deve ser dado ao grupo 6, comprometidos normativa-afetivamente, segunda maior média na dimensão analisada; e 7, comprometidos normativa-instrumentalmente, porquanto, mesmo que suas médias se aproximem da média do grupo 1, apresentaram importância relativa nas atividades de treinamento e desenvolvimento.

Apesar de ter apresentado fraca correlação com os componentes do comprometimento, o salário demonstrou uma diversificação entre as médias de quase todos os clusters, adquirindo importância relativa para cada um. O comprometido nas três dimensões apresentou médias superiores, quando comparadas àquelas dos descomprometidos totalmente, comprometidos afetivamente, instrumentalmente, normativamente, afetiva-instrumentalmente e normativa-afetivamente. O grupo 4, comprometidos afetivamente, apresentou a média mais baixa com relação à importância dada ao salário.

$\mathrm{O}$ relacionamento com a chefia consiste em tópico de relevo na empresa. $\mathrm{O}$ comprometido nas três dimensões apresenta escores elevados nesse item com relação a todos os grupos. As comparações significativas, no entanto, correspondem aos clusters 2, 3, 4, 5 e 8 -respectivamente: descomprometidos em todas as dimensões, comprometidos só normativamente, só afetivamente, só instrumentalmente e comprometidos afetiva-instrumentalmente. O cluster 7, que corresponde aos comprometidos normativa-instrumentalmente, obteve o segundo lugar no item analisado e pode ser relacionado aos grupos anteriores, considerando-se que são significativas tais comparações. No grupo 1, apesar de a média ser superior ao grupo 7, as diferenças entre as médias não foi considerada signi- 
ficativa pela análise, indicando provavelmente uma similaridade no que tange à importância dada a essa variável. O mesmo pode ser dito com relação ao sexto cluster.

Houve diferenças, ainda, referentes ao planejamento de carreira da empresa. Os escores médios foram baixos, atingindo o máximo de 3,7509, talvez em função de que a organização pesquisada pertence ao setor público e, por esse motivo, seus critérios de promoção e planejamento de carreira são rígidos e preestabelecidos. O grupo dos totalmente comprometidos obteve escores médios superiores àqueles dos grupos dos descomprometidos nas três dimensões, comprometidos instrumentalmente e comprometidos afetiva-instrumentalmente. O sexto conglomerado, os normativa-afetivamente vinculados, representa a maior média para essa variável e estabeleceram pontuação maior e mais significativa do que os grupos dos totalmente descomprometidos, dos comprometidos instrumentalmente, afetiva-instrumentalmente, normativa e afetivamente.

O ambiente físico e a comunicação mostraram-se também mais importantes para os comprometidos nas três dimensões, e sua segunda maior média convergiu para o grupo dos comprometidos normativa-afetivamente, que se apresentou com escores médios superiores àqueles dos grupos só normativos e só afetivos. O cluster que menos se interessa por essa dimensão, com a menor média, é o grupo dos comprometidos instrumentalmente.

O ambiente de trabalho teve maior média para o primeiro cluster, sendo seguido pelos comprometidos normativa-afetivamente. $\mathrm{O}$ grupo 1, quando comparado ao grupo dos vinculados normativamente, instrumentalmente e descomprometidos nas três dimensões apresentou diferenças significativas. Conquanto os menores escores, nessa dimensão, tenham sido para os grupos 3 e 5, o valor mínimo observado atingiu 3,4579, indicando que o ambiente de trabalho deve ser levado em consideração para todos os padrões do comprometimento.

Visando a caracterizar os padrões de comprometimento de acordo com os dados pessoais e funcionais da amostra, foi feita a tabulação cruzada entre estes últimos e os clusters encontrados. O teste qui-quadrado foi conduzido por meio do SPSS; a maioria dos cruzamentos apresentaram coeficiente em níveis superiores ao valor crítico da distribuição qui-quadrada, implicando a rejeição da hipótese da não associação entre as variáveis (vide Tabela 8). 


\section{Tabela 8: Teste Qui-Quadrado}

\begin{tabular}{l|c|c|c|c|c|c}
\hline & \multicolumn{3}{|c|}{ Valores Observados } & \multicolumn{3}{c}{ Valores Críticos } \\
\hline Tabulação & $\begin{array}{c}\text { Pearson } \\
\text { Qui-quadrado }\end{array}$ & Df & Sig. & $\begin{array}{c}\text { Pearson } \\
\text { Qui-quadrado }\end{array}$ & Df & Sig. \\
\hline Sexo & 14,258 & 7 & 0,047 & 2,167 & 7 & 0,05 \\
\hline Idade & 67,573 & 28 & 0,000 & 16,928 & 28 & 0,05 \\
\hline Escolaridade & 67,533 & 42 & 0,007 & 18,493 & 30 & 0,05 \\
\hline Estado civil & 45,627 & 30 & 0,108 & 20,599 & 30 & 0,01 \\
\hline Tempo na empresa & 90,306 & 35 & 0,000 & 18,493 & 30 & 0,05 \\
\hline Cargos & 48,806 & 14 & 0,000 & 6,571 & 14 & 0,05 \\
\hline Função & 15,644 & 7 & 0,029 & 2,167 & 7 & 0,05 \\
\hline Nível salarial & 92,298 & 49 & 0,000 & 18,493 & 30 & 0,05 \\
\hline Satisfação geral & 121,610 & 28 & 0,000 & 16,928 & 28 & 0,05 \\
\hline Fone: das
\end{tabular}

Fonte: dados da pesquisa.

Como a inscrição no sindicato e a atividade vital ficaram com índices não significativos, optou-se por retirá-las da caracterização dos grupos. A caracterização completa pode ser sintetizada da seguinte forma, após análise cuidadosa das tabelas geradas pelo cruzamento dos dados:

- Cluster 1, comprometidos nas três dimensões: representa apenas 3,2\% da amostra, a centralidade da vida é caracterizada pela família, em primeiro lugar, trabalho e estudo. São influenciados por todas as práticas de $\mathrm{RH}$, mas principalmente pelo treinamento e desenvolvimento, ambiente de trabalho e relacionamento com a chefia. $\mathrm{O}$ ambiente físico, planejamento da carreira e salário apresentaram importância relativa.

- Cluster 2, descomprometidos nas três dimensões: corresponde a $29 \%$ da amostra, a centralidade da vida focaliza a família, com $62 \%$ e, em segundo lugar, o trabalho com $27 \%$ dos que pertencem ao grupo. Conquanto represente apenas $3,3 \%$ do cluster, $30,8 \%$ dos que responderam que a atividade mais importante da vida consiste nos estudos ou leituras pertencem a ele. Nesse grupo as variáveis de RH não apresentaram importância significativa.

. Cluster 3, comprometidos normativamente: composto por $14,8 \%$ da amostra, segundo maior grupo dos comprometidos, o salário máximo do grupo é de até 7 salários mínimos (90\%). A família e o trabalho concentram as atividades mais importantes da vida; mas dos que escolheram estudo/leituras, $15,4 \%$ também fazem parte do terceiro cluster. As práticas de RH que mais afetam o grupo em foco são o treinamento e desenvolvimento, relacionamento com a chefia e o ambiente de trabalho. 
. Cluster 4, comprometidos afetivamente: o maior grupo dos comprometidos, possuindo $19,2 \%$ da amostra. Aparecem funcionários que exercem alguma função de supervisão. Pouco destaque ao salário, mas são importantes as atividades de treinamento e desenvolvimento, ambiente de trabalho, relacionamento com a chefia, comunicação e ambiente físico.

. Cluster 5, comprometidos instrumentalmente: corresponde a $12,2 \%$ da amostra. A maioria possui menos de 10 anos de empresa e apresenta o menor índice salarial: $48 \%$ recebem até 3 salários mínimos e $46 \%$ estão entre 3 e 7 salários mínimos. Apresenta a família, o trabalho e estudo/leituras como atividades mais importantes da vida. Baixa pontuação e correlação em todas as práticas de recursos humanos.

. Cluster 6, comprometidos normativa-afetivamente: representa 9,5\% da amostra. A centralidade da vida está na família e, em segundo lugar, no trabalho. O treinamento e desenvolvimento aparece em primeiro plano, seguido da relação com a chefia e com o ambiente de trabalho. As outras práticas apresentaram escore médio elevado nesse grupo.

- Cluster 7, comprometidos normativa-instrumentalmente: 5,6\% da amostra e a família e o trabalho também se apresentam nessa ordem de importância para o grupo. A relação com a chefia é uma dimensão influente no nível de comprometimento; no entanto a carreira parece não afetar muito o grupo. $\mathrm{O}$ treinamento e desenvolvimento e ambiente de trabalho se destacam.

- Cluster 8, comprometidos afetiva-instrumentalmente: com $6,1 \%$ da amostra, o treinamento e desenvolvimento e relação com chefia constituem as práticas mais relevantes para o grupo, seguidas do ambiente de trabalho e da comunicação e ambiente físico.

Importante relembrar que o recrutamento e seleção e o sistema de remuneração não apresentaram diferenças significativas para os grupos, ao contrário do que ocorreu com o treinamento e desenvolvimento, talvez porque as primeiras práticas são vinculadas ao controle do Governo e os funcionários tenham consciência da rigidez do sistema público, cujo modo de funcionamento impede grandes modificações nesses dois aspectos.

$\mathrm{O}$ ambiente de trabalho, que engloba basicamente aspectos do clima social existente em cada setor, mostrou-se fortemente correlacionado ao comprometimento afetivo, em primeiro lugar, e normativo, em segundo. Corresponde a uma prática em que a ECT possui liberdade de ação e em que pode influenciar, ainda que tenha apresentado média pouco significativa com relação ao vínculo normativo, instrumental e afetivo-instrumental. 


\section{À GuISA de CONCLUSÕES}

O título À Guisa de Conclusões sugere que o trabalho não está terminado. Há ainda muitas ações a serem tomadas, questões que se formulam a partir dos resultados alcançados, dúvidas que permeiam o cenário acadêmico e empresarial. E é nesse sentido que esse título se justifica, representando o cuidado dos autores deste artigo em se mostrarem abertos a sugestões e opiniões construtivas, que certamente crescerão em conteúdo e qualidade.

A pesquisa realizada consistiu, fundamentalmente, em responder até que ponto as políticas de recursos humanos de uma empresa de serviços do setor público interferem no comprometimento organizacional de seu funcionário. Essa questão central pôde ser concluída graças à técnica estatística de correlação bivaria$\mathrm{da}$, em que se constatou que apenas as dimensões normativa e afetiva do constructo apresentaram uma linearidade positiva com a gestão de RH.

Dessa forma, tornou-se evidente que as variáveis de recursos humanos investigadas influenciam as dimensões normativa e afetiva do comprometimento, mas apresentaram correlações fracas com o comprometimento instrumental. Os índices mais elevados são observados nas atividades de treinamento e desenvolvimento, denotando que constituem fator primordial dentro do corpo funcional, no que se refere a manter os estilos de comprometimento apontados. A essa prática é atribuída a função de manter elevados os níveis de compromisso, motivação e satisfação do corpo funcional; a empresa apresenta certa liberdade de atuação em promover alguns cursos, palestras e treinamentos. Em princípio, parece que os dirigentes têm consciência disso e concentram seus recursos e sua atenção nesse aspecto, tentando modernizar, de alguma forma, o sistema.

As políticas de RH da Empresa de Correios e Telégrafos seguem padrões tradicionais, apresentando subgerências específicas para cada função que exercem. A consciência de que deve ser competitiva para enfrentar o mercado está presente na forma de gestão da empresa que, mesmo estando atrelada às decisões de órgãos públicos para direcionar sua forma de gestão, busca um modelo mais participativo, com foco em seu corpo funcional. A área de recursos humanos tem o escopo, assim, de provocar algumas reações de forma a criar respostas adequadas às demandas externas. Nesse aspecto, defende-se que há um esforço de mudança na forma de gestão adotada.

O concurso público, desde a promulgação da Constituição do Brasil em 1988, constitui o principal método de recrutamento e seleção, estando a decisão de contratação vinculada ao parecer final do Governo Federal. Assim também ocorre 
com a progressão na carreira, já que a mobilidade funcional pode ser conseguida apenas por meio dos concursos. Pode-se afirmar, assim, que não existe plano de carreira na ECT.

A estrutura hierárquica e o sistema de cargos e salários são considerados antigos e precisam de reformulação urgente. Obviamente qualquer modificação nesses aspectos requer concordância de órgãos superiores, sendo esse processo moroso, mas adequado ao sistema burocrático do Estado. O piso salarial encontra-se em um patamar razoável e os benefícios oferecidos pela empresa parecem adequar-se às necessidades dos funcionários.

Os pontos críticos observados na gestão de recursos humanos da Empresa de Correios e Telégrafos estão estreitamente relacionados com o fato de esta pertencer ao setor público. Sendo subordinada ao Governo e à sua forma de administração, alguns aspectos tornam-se difíceis de ser modificados, dado que têm de obedecer ao rigor da lei a que estão sujeitos. Tais limites impõem também um enrijecimento em toda a estrutura de funcionamento dos órgãos públicos. Como ilustração, o sistema de recrutamento e seleção e o sistema de remuneração, assim como o plano de carreira são áreas que, por ora, não podem mudar sua linha de atuação.

Em alguns setores que possuem autonomia, a ECT pode agir em regime de cooperação entre funcionários e chefias; por exemplo, com relação ao ambiente físico e comunicação, aspectos importantes para o bem-estar do funcionário. Observou-se que essas variáveis apresentaram índice significativo na correlação bivariada, especialmente para o comprometimento normativo. Ainda que objetivem ser bem regulamentados e eficientes, a comunicação e o ambiente físico apresentaram médias relativamente baixas para os comprometidos normativamente; para os normativo-afetivos e normativo-instrumentais, essas médias se elevaram um pouco. Como podem ser manipuladas pela empresa, propõe-se que os dirigentes destinem especial atenção a essa área, de forma a desenvolver e manter elevado o grau de compromisso do empregado com a empresa.

A assessoria de comunicação tem o poder de integrar o funcionário à ECT, estimulando sua participação efetiva em algumas decisões mais elementares, tais como situações em que ele possa emitir opiniões sobre o ambiente físico de trabalho, dar sugestões sobre cursos ou idéias para melhorar a produtividade ou o ambiente social, contribuir para o jornal, promover eventos culturais etc. Paralela a isso, a própria chefia pode organizar-se para uma comunicação transparente, conscientizando os funcionários sobre o que é esperado deles e sobre a importância de suas funções, bem como dando-lhes liberdade de expressão. Um corpo funcional motivado e efetivamente comprometido com certeza trará resultados positivos para a empresa como um todo. 
Ademais, o relacionamento com a chefia representa um item importante e determinante na construção de um ambiente social agradável e produtivo, haja vista a alta correlação demonstrada com a dimensão normativa e afetiva do comprometimento. Ainda assim, as médias com os normativos, afetivos, instrumentais e afetivo-instrumentais situaram-se em nível não muito elevado. A consciência individual do papel relevante que o funcionário exerce na empresa como um todo possivelmente melhoraria a percepção dessa variável. Mais uma vez se evidencia a importância do modo como as informações são transmitidas dentro da empresa.

Através do treinamento, como demonstram algumas sugestões dos próprios funcionários, haveria ainda a possibilidade de conjugar a atuação dos supervisores e gerentes e conseqüente ambiente de trabalho satisfatório. $\mathrm{O}$ treinamento e desenvolvimento representou a mais alta correlação com os comprometimentos normativo e afetivo, além dos altos índices médios em quase todos os padrões. O objetivo da empresa é manter elevados esses indicativos, de modo a ter sempre a satisfação geral do funcionário em patamares significativos. Nesse sentido, também se sente livre para utilizar essa prática, cuja limitação se concentra tão somente nas restrições orçamentárias.

Em princípio, a intenção da ECT de modernização parece concreta e fundamentada na disponibilidade para que esta pesquisa se processasse em seu âmbito interno. Nota-se claramente que não é preciso radical redefinição de papéis e da forma de gestão, uma vez que a empresa vem acompanhando as mudanças, superando crises e mantendo sua posição competitiva no mercado. $O$ fato de sua atenção estar voltada para o comprometimento do empregado reflete a preocupação dos dirigentes acerca das tendências comportamentais e gerenciais de um cenário turbulento e em constante mutação.

O segmento público, estando circunscrito a legislações, normas e procedimentos arraigados e sedimentados a modelos de gestão ultrapassados, deve procurar formas inovadoras dentro do universo em que pode atuar. Assim, a dificuldade de agir é evidente, principalmente no que tange ao sistema de RH. Por esses motivos, destaca-se a importância e o esforço de se conduzir uma investigação empírica nessas condições, e ainda a ousadia de apresentar sugestões com o intuito de aprimorar, cada vez mais, a qualidade dos serviços prestados pela empresa, mediante a manutenção de um vínculo construtivo e positivo dos empregados com ela.

As pesquisas sobre o tema comprometimento no Brasil têm-se restringido à linha atitudinal-afetiva ou comportamental (Borges-Andrade, 1989; Brandão, 1991; Dias, 1993; Pena, 1995; Moraes e Marques, 1996; Zehuri, 1997) e, ainda, pesquisar formas de comprometimento com o sindicato, carreira e organização 
(Bastos, 1994). Trazer a abordagem de múltiplos comprometimentos para os trabalhos acadêmicos amplia o campo de investigação, por meio de uma proposição mais complexa de se analisar esse vínculo.

A proposta de Meyer e Allen (1997) enriquece as abordagens teóricas do tema, a partir da premissa de que um indivíduo pode apresentar diferentes manifestações de seu envolvimento com a organização, e não apenas possuir uma única dimensão comportamental. O modelo de Meyer e Allen $(1984,1991,1997)$ revelou-se mais coerente com o ambiente interno e externo que se desenha no cenário globalizado e, reforçar essa linha de estudos no Brasil, parece estar mais em consonância com a complexidade do ser humano e com as contínuas e constantes transformações sócio-econômicas.

A presente pesquisa constitui o segundo trabalho no Brasil, de que se tem conhecimento, a lançar mão dessa abordagem. Além disso, o agrupamento da amostra em padrões de comprometimento traz a possibilidade de se fazer uma intervenção real no grupo, permitindo à pesquisa acadêmica transcender o campo teórico e direcionar-se para uma atuação prática, coerente com a realidade mais dinâmica do meio empresarial e acompanhando as tendências do cenário mundial.

Outro legado desta pesquisa para investigações futuras e orientação de trabalhos posteriores é a validação de um novo instrumento de pesquisa, construído sob o respaldo de teorias e das entrevistas efetuadas, além de demonstrar a simplicidade do processo de validação de escalas. Potenciais seguidores do presente trabalho provavelmente sentir-se-ão mais seguros, ante os processos estatísticos, com os procedimentos metodológicos aqui explicitados.

A compreensão integral de um processo de pesquisa é importante, uma vez que fornece subsídios, a quem a está conduzindo, para a obtenção consciente de resultados confiáveis e fidedignos. Antes de mais nada, no entanto, é preciso conhecer aonde se quer chegar e premunir-se de constância para superar os desafios e obstáculos que poderão surgir. Como nos ensina um provérbio inglês: "Onde existe uma vontade, há o caminho".

As recomendações propostas tiveram o intuito de evidenciar que uma investigação não se encontra concluída em termos definitivos. Essa atitude demonstra uma ampliação dos horizontes da pesquisa e a tendência e necessidade de atualização constante dos conhecimentos do próprio pesquisador. 


\section{NotAs}

${ }^{1}$ Do inglês, significa trocas laterais.

${ }^{2}$ Tradução livre da autora deste artigo.

${ }^{3}$ Por ser de tamanho considerável, não será apresentada neste trabalho.

\section{REFERÊNCIAS BibLIOGRÁFICAS}

ASHFORTH, B. E.;

SAKS, A. M.

Socialization tactics : longitudinal effects on newcomer adjustment. Academy of Management Journal, v. 39, p. 149-178, 1996.

BASTOS, A. V. B.

Comprometimento organizacional : um balanço dos resultados e desafios que cercam essa tradição de pesquisa. Revista de Administração de Empresas, v. 3, n. 33, p. 52-64, maio/jun. 1993.

\section{Comprometimento no trabalho :} a estrutura dos vínculos do trabalhador com a organização, a carreira e o sindicato. Brasília, 1994. Tese (Doutorado em Psicologia) - Universidade de Brasília.

\section{BECKER, H. S.}

Notes on the concept of commitment. The American Journal of Sociology, v. 66, n. 1, p. 32-40, 1960.
ETZIONI, A.

Análise comparativa de organizações complexas : sobre o poder, o engajamento e seus correlatos. Rio de Janeiro : Zahar, 1975.

GIL, A. C.

Como elaborar um projeto de pesquisa. São Paulo: Atlas, 1987.

MEDEIROS, C. A. F.

Comprometimento organizacional, características pessoais e performance no trabalho : um estudo dos padrões de comprometimento organizacional. Natal, 1997. Dissertação (Mestrado em Administração) - Universidade Federal do Rio Grande do Norte.

MEYER, J. P.;

ALLEN, N. J.

Testing the "side-bet theory" of organizational commitment: some methodological considerations. Journal of Applied Psychology, v. 69, n. 3, p. 372-378, Aug. 1984. 
A three-component conceptualization of organizational commitment. Human Resource Management Review, v. 1, p. 61-89, 1991.

\section{Commitment in the workplace:} theory, research and application. London : Sage Publications, 1997.

MOWDAY, R. T.;

STEERS, R. M.;

PORTER, L. W.

The measurement of organizational commitment. Journal of Vocational Behavior, v. 14, p. 224-247, 1982.

NORUSIS, M. J.

SPSS - professional statistics. Chicago : SPSS Inc., 1997.

SÁ, M. A. D.;

LEMOINE, C.

$\mathrm{O}$ estilo de liderança como fator de comprometimento na empresa. In: XXII ENCONTRO ANUAL DA ANPAD (1998 : Foz do Iguaçu). Anais Eletrônicos... Porto Alegre : Microservice Microfilmagens e Reproduções Técnicas, 1998.
SAKS, A. M.

Longitudinal field investigation of the moderating and mediating effects of self-efficacy on the relationship between training and newcomer adjustment. Journal of Applied Psychology, v. 80, p. 211-225, 1995.

STEIL, A. V.;

SANCHES, E. N.

Comprometimento organizacional como uma estratégia de controle. In: XXII ENCONTRO ANUAL DA ANPAD (1998 : Foz do Iguaçu). Anais Eletrônicos... Porto Alegre : Microservice Microfilmagens e Reproduções Técnicas, 1998.

TANNENBAUM, S. I. et al.

Meeting trainees' expectations : the influence of training fulfillment on the development of commitment, self-efficacy, and motivation. Journal of Applied Psychology, v. 76, p. 759-769, 1991.

WEINER, Y.

Commitment in organizations : a normative view. Academy Management Review, v. 7, p. 418-428, 1982. 